\title{
TITLE: ANISOTROPY AND SPATIAL VARIATION OF RELATIVE PERMEABILITY AND LITHOLOGIC CHARACTER OF TENSLEEP SANDSTONE RESERVOIRS IN THE BIGHORN AND WIND RIVER BASINS, WYOMING
}

\author{
D.O.E. Contract No.: DE-AC22-93BC14897
}

Contractor Name and Address: Institute for Energy Research, University of Wyoming, P.O.Box 4068 , Laramie, Wyoming 82071

Date of Report: July 20, 1995

Award Date: September 15, 1993

Completion Date: September 14, 1996

Government Award for Current Fiscal Year: $\$ 251,061$

Principal Investigator and Project Manager: Thomas L. Dunn

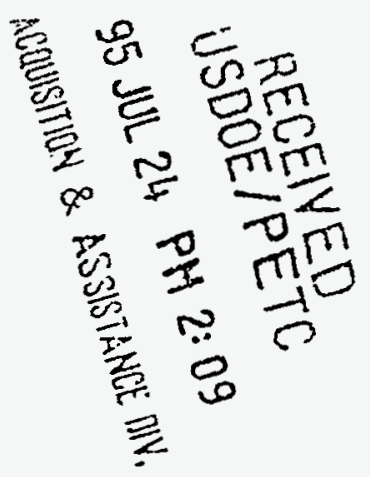

Reporting Period: April 1, 1995 - June 30, 1995

\section{Objectives}

This multidisciplinary study is designed to provide improvements in advanced reservoir characterization techniques. This goal is to be accomplished through:

1. An examination of the spatial variation and anisotropy of relative permeability in the Tensleep Sandstone reservoirs of Wyoming;

2. The placement of that variation and anisotropy into paleogeographic, depositional, and diagenetic frameworks;

3. The development of pore-system imagery techniques for the calculation of relative permeability; and

4. Reservoir simulations testing the impact of relative permeability anisotropy and spatial variation on Tensleep Sandstone reservoir enhanced oil recovery.

Concurrent efforts are aimed at understanding the spatial and dynamic alteration in sandstone reservoirs that is caused by rock-fluid interaction during $\mathrm{CO}_{2}$-enhanced oil recovery processes. This work focuses on quantifying the relationship of fluid-rock interaction with lithologic characterization (in terms of changes in relative permeability, wettability, and pore structure) and with fluid characterization (in terms of changes in chemical composition and fluid properties.) This work will establish new criteria for the susceptibility of Tensleep Sandstone reservoirs to production-induced formation alteration that results in change in relative permeability and in wellbore scale damage. 


\section{DISCLAIMER}

Portions of this document may be illegible in electronic image products. Images are produced from the best available original document. 
This task will be accomplished by:

1. Flow experiments using core material;

2. Examination of regional trends in water chemistry;

3. Examination of local water chemistry trends at field scale; and

4. Chemical modeling of both the experimental and reservoir systems in order to scale up the experiments to field scale.

\section{Summary of Technical Progress}

\section{Regional Frameworks}

The regional framework task objective is to associate spatial distributions and anisotropy of relative permeability with the depositional subfacies and zones of diagenetic alteration found within the Tensleep Sandstone. The working premise is that the associations between depositional lithofacies, diagenetic alteration, and pore geometry will strongly link relative permeability with the distinct and measurable dimensions of lithofacies and authigenic mineral facies.

Regional porosity and gamma-ray log correlations of Tensleep Sandstone dolomitesandstone cycles have been constructed over the entire Bighorn Basin (Figures 1 and 2). These correlations demonstrate that at least six dolomite-sandstone cycles can be recognized and distinguished. Gross and net sand maps utilizing this correlation indicate variations in the thickness of individual sandstone units. These thickness variations can be related to increased subsidence in those areas during deposition of the Tensleep Sandstone.

During May, Dr. Mary Crabaugh presented the project's work on flow unit geometries and characteristics in the Tensleep to geologists and engineers at the Marathon Oil Company Petroleum Technology Center in Littleton, Colo. Because of interest in the work, a field study of the Tensleep Sandstone in the Northern Oregon Basin field has been initiated with Marathon Oil Company. This study will involve well-log correlation, core description, and computer simulation of bounding surfaces within the subsurface utilizing FMI logs from horizontal wells. The use of FMI and FMS logs will prove invaluable in understanding the stratification variations in the subsurface of the western Bighorn Basin where there are no significant outcrops.

Access has been granted by the Shoshone and Arapaho Tribes to outcrops on the Wind River Indian Reservation. Field work is planned for the months of July, August, and September 1995 and will concentrate on outcrops in the Wind River Basin. The main objectives are to determine if the style and geometries of stratification and of bounding surfaces in the Wind River Basin are the same as those observed in outcrops and cores from the Bighorn Basin. This data will increase the areal extent of our examination of flow-unit geometries for the Tensleep Sandstone in the Wind River Basin.

\section{Relative Permeability Measurements}

The focus of this task is to obtain quantitative laboratory data on the magnitude and variability of relative permeability anisotropy and spatial variation of the dominant reservoir and boundary surface lithologies of the Tensleep Sandstone. Relative permeability is being measured using the unsteady-state technique. An additional objective of this study is to provide algorithms for calculating relative permeability from quantitative pore imagery data. This latter study is just underway. 
Relative permeability measurements continue in the laboratory with Tensleep Sandstone cores. Samples from the subsurface are now being used, and a total of 20 cores (10 horizontal/vertical pairs) have been assembled for laboratory measurements. Relative permeability measurements have been completed for eight samples. All 20 cores have been cleaned and absolute dry-air permeability measured. As expected, these subsurface samples have lower permeability than the samples collected on the surface. The laboratory apparatus was modified to allow up to 50 psi pressure, in order to accommodate this lower permeability. The measurements on these samples will be completed next quarter.

\section{Simulation}

A simple one-dimensional Buckley-Leverett model for water flooding is being used to simulate the displacement of oil on a reservoir scale. The program is run once with parameters typical of horizontal relative permeability, and again with parameters for vertical relative permeability. Results of the two runs are then compared to assess the effects of relative permeability anisotropy. The method of characterizing relative permeability parameters for input to the simulator is being assessed. The relative-permeability-versus-water-saturation data are fit with a power-law function that can be input directly to the Buckley-Leverett based computer program. A steeper slope (higher power-law exponent) is used for vertical relative permeability. More "piston-like" displacement is then obtained, and very little oil is recovered after water breakthrough.

\section{Pore Image Analysis}

The purpose of this pore image analysis study is to create a low-cost research and development tool to analyze the spatial distribution and anisotropy of relative permeability in sandstone reservoirs. The approach utilizes polished thin sections from Tensleep Sandstone samples whose relative permeability has been measured. A digital image of the pore system is acquired using a back-scattered electron detector mounted on a scanning electron microscope. The image is processed using standard erosion-dilation analysis, and a correlation is built between the image and the relative permeability data. Initial results indicate that the anisotropy observed in the relative permeability is observed in pore-size variations. The establishment of repeatable, reliable, and well understood procedures for sampling, epoxy impregnation, and image processing will be the focus of the next quarter.

\section{$\mathrm{CO}_{2}$ Flood - Formation Alteration and Wellbore Damage}

In this task, criteria are established for the susceptibility of Tensleep reservoirs to formation alteration which result in a change in absolute or relative permeability and possible wellbore scale damage during $\mathrm{CO}_{2}$ enhanced oil recovery. This advanced reservoir characterization criteria will be used to optimize recovery efficiency. This task includes:

1. Flow experiments on core material to examine the effects of $\mathrm{CO}_{2}$ flooding on the alteration of the fluid and rock system;

2. Examination of regional trends in water chemistry;

3. Examination of local water chemistry trends at field scale; and

4. Chemical modeling of both the reservoir and experimental systems in order to scaleup the experiments to reservoir conditions. 
The third $\mathrm{CO}_{2}$ core-flooding experiment was successfully carried out at the Petroleum Technology Center, Marathon Oil Company, Littleton, CO. It was run using subsurface cores from the Oregon Basin oil field and synthetic Type B water in terms of this project's definition for Tensleep water chemistry at $80^{\circ} \mathrm{C}$ and 166 bars $\left(\mathrm{P}_{\mathrm{CO}_{2}}=\mathrm{P}_{\text {total }}\right)$. The total run duration was 178 hours, which was much longer than those of the previous two runs (first experiment: 60 hrs; second experiment: $48 \mathrm{hrs}$ ). Major elements were analyzed at the Marathon Oil Company. Through those analytical data, it was determined that precipitation of anhydrite is an important reaction that contributes in controlling solution chemistry and physical properties of core, such as permeability, as well as dissolution of dolomite. Minor and trace element analysis of obtained effluent solutions is in progress.

The computer simulation of scale formation due to $\mathrm{CO}_{2}$ flooding is being refined in order to take into account the effect of precipitation of anhydrite, the importance of which was shown through the $\mathrm{CO}_{2}$ core-flooding experiment. Compilation of Tensleep formation water chemistry continued with the collection of fifteen additional formation-water chemistry analyses from the Tensleep Formation in the Wind River Basin obtained from the Wyoming State Geological Survey and the literature.

\section{Project Management and Technology Transfer}

The administrative task provides for effective coordination and integration of the project's research tasks, and for the coordination and timely reporting of results to its Industry Advisor/Mentors, the Department of Energy, and the scientific and engineering communities.

A progress report was presented at the Department of Energy contractor's meeting in June. As mentioned above, a presentation on the Tensleep flow unit dimensions was made to Marathon Oil Company personnel in May. That contact has initiated additional joint work on horizontal well development in the Tensleep.

A website for project results and updates was established. Interested parties may access this site at:

$$
\text { (http://garfield.uwyo.edu/doe/tensleep.html) }
$$

In the near future, this site will contain additional detailed information, data, and updates on conclusions reached.

\section{DISCLAIMER}

This report was prepared as an account of work sponsored by an agency of the United States Government. Neither the United States Government nor any agency thereof, nor any of their employees, makes any warranty, express or implied, or assumes any legal liability or responsibility for the accuracy, completeness, or usefulness of any information, apparatus, product, or process disclosed, or represents that its use would not infringe privately owned rights. Reference herein to any specific commercial product, process, or service by trade name, trademark, manufacturer, or otherwise does not necessarily constitute or imply its endorsement, recommendation, or favoring by the United States Government or any agency thereof. The views and opinions of authors expressed herein do not necessarily state or reflect those of the United States Government or any agency thereof. 


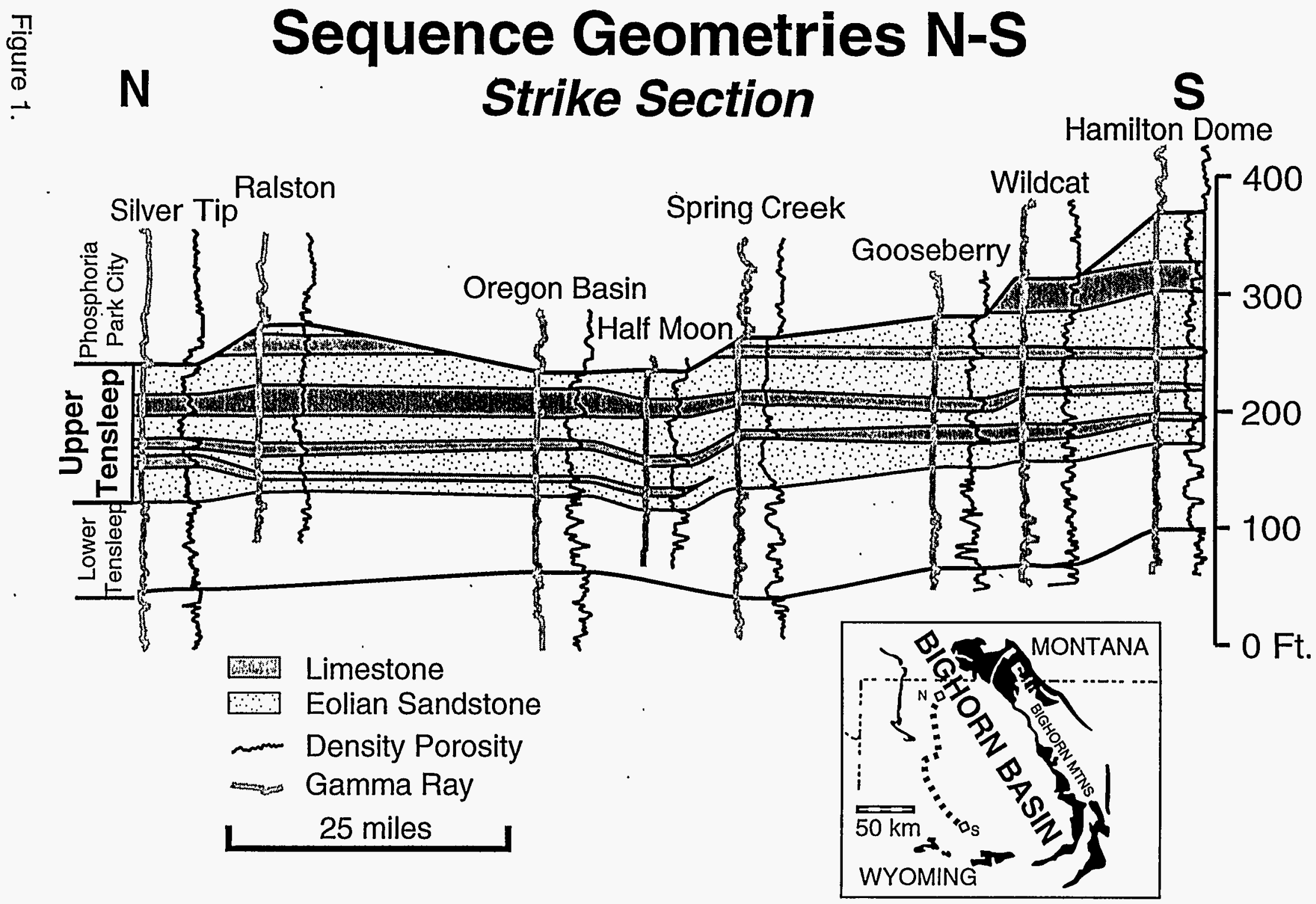




\section{莫 \\ Sequence Geometries E-W \\ W Dip Section}

E

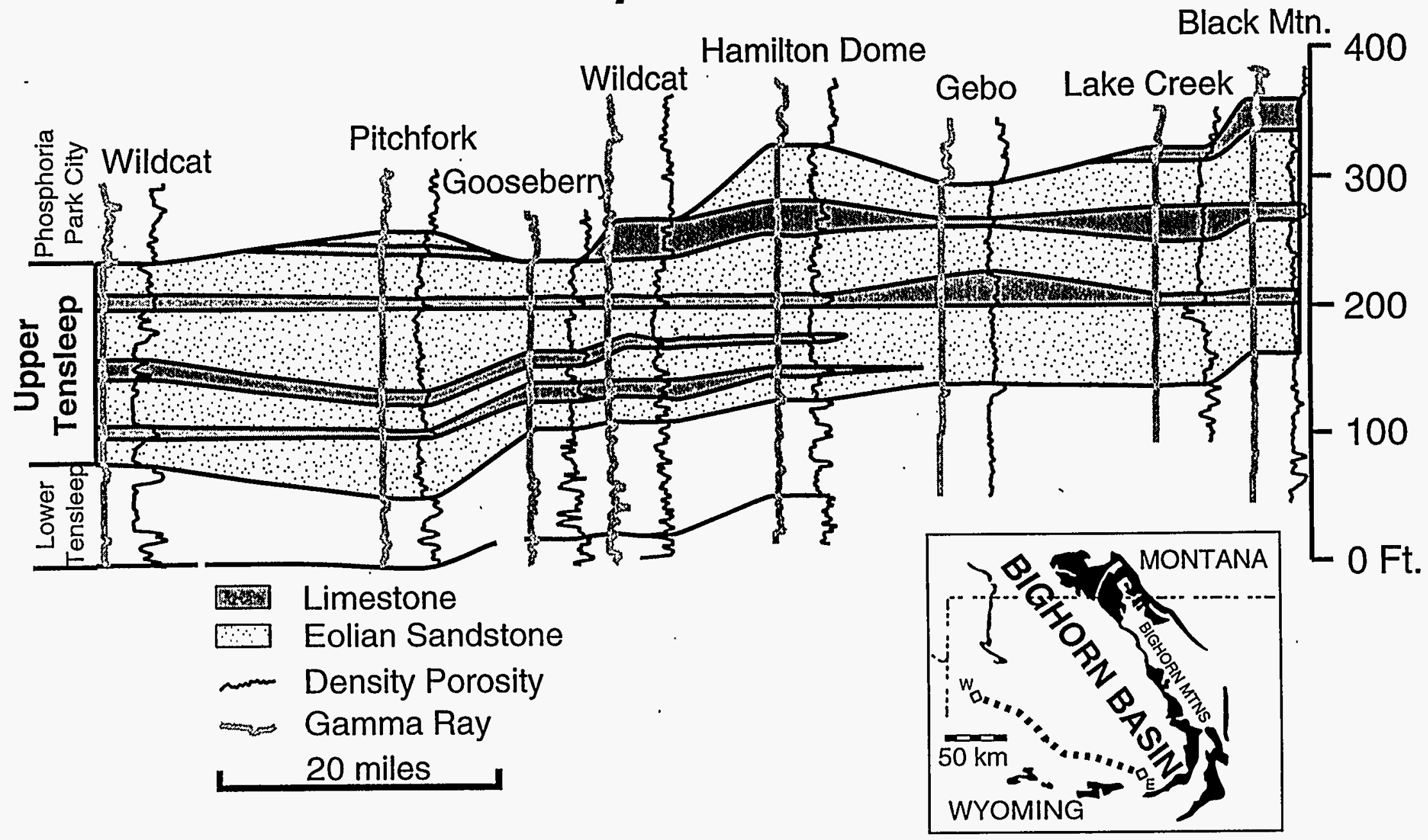

